RUNNING HEAD: business owners’ success criteria

KEY WORDS: Business owners, success, personal values.

Reference: Gorgievski, M.J., Ascalon, M.E. \& Stephan, U. (2011). Small business owners' success criteria, a values approach to personal differences. Journal of Small Business Management, 49, 207-232.

\title{
SMALL BUSINESS OWNERS' SUCCESS CRITERIA, A VALUES APPROACH TO PERSONAL DIFFERENCES *
}

Authors: Marjan J. Gorgievski, M. Evelina Ascalon, and Ute Stephan

Dr. Marjan Gorgievski received her Ph.D. in Occupational Health Psychology from Utrecht University. She works as an assistant professor at the Department of Psychology, Erasmus University Rotterdam, The Netherlands. Her research focuses on the bi-directional relationship between well-being and performance, and psychological aspects of entrepreneurship. She has published several book chapters and theoretical and empirical articles in international journals on business owners' well-being, financial business performance, stress and work-engagement.

Dr. Evelina Ascalon received her Ph.D. in Industrial and Organizational Psychology from the University of Tulsa. She currently works as a Senior Consultant for Ruegg Consulting in Switzerland. She conducted the study presented in this article as a post-doctoral researcher at the Erasmus University. Her main areas of interest include: Entrepreneurship, Leadership Development, Cross-cultural Issues, Performance Assessment, Training and Evaluation.

Dr. Ute Stephan received her Ph.D. in natural sciences/psychology from the University of Marburg. She currently works as a senior researcher at the Department of Managerial Economics, Strategy and Innovation at the Katholieke Universiteit Leuven, Belgium. Her research focuses on cultural influences on entrepreneurship and psychological approaches explaining commercial and social entrepreneurs' motivation, health and success. All authors are founding members of the council of the International Network of Psychology of Entrepreneurship Research and Education (INPERE).

* The authors want to thank Marlot Bal, M.Sc. for assisting in the literature review, and Samantha Bouwmeester, Ph.D. for her valuable advise concerning data-analysis.

Correspondence concerning this article should be addressed to Marjan Gorgievski, Ph.D., Erasmus University Rotterdam, Department of Psychology, T13-03, P.O. Box 1738, NL-3000 DR Rotterdam, The Netherlands. Tel. +31 1040888799 . Fax. +31 104089009. Email: Gorgievski@fsw.eur.nl 


\section{SMALL BUSINESS OWNERS' SUCCESS CRITERIA, A VALUES APPROACH TO PERSONAL DIFFERENCES}

This study of 150 Dutch small business owners, identified through business/network directories, investigated relationships between owners' understanding of success and their personal values. Business owners ranked ten success criteria. Personal satisfaction, profitability and satisfied stakeholders ranked highest. Multidimensional scaling techniques revealed two dimensions underlying the rank order of success criteria: person-oriented (personal satisfaction versus business growth) and business-oriented (profit versus social contribution). Furthermore, business growth, profitability and innovativeness were guided by self-enhancing value orientations (power and achievement). Softer success criteria, such as having satisfied stakeholders and a good work - life balance were guided by selftranscendent value orientations (benevolence and universalism).

KEY WORDS: Small business owners, success, business performance, personal values. 


\section{SMALL BUSINESS OWNERS’ SUCCESS CRITERIA, A VALUES APPROACH TO PERSONAL DIFFERENCES}

The acquisition of wealth, recognition, and growth has been considered the normative criteria by which business owners have been judged to be successful for the past decades (cf. Julien, 1998; Littunen, 2000; Wang, Watkins, Harris, \& Spicer, 2004). This has greatly influenced research and theorizing to date, but it remains unclear to what extent these criteria reflect the success criteria that business owners indeed apply to determine whether or not they are successful. Moreover, the underlying motivators for individual differences in evaluations of entrepreneurial success are still largely unknown.

Our objective is to contribute to small business and entrepreneurship research and education, by providing a more comprehensive understanding of the way business owners evaluate success, and business owners' personal values as its potential predictors. Current research and education emphasizes success criteria relating to technical aspects of management and finances with the goal of maximizing profit and growth (cf., Wilson, 2004). However, building on a review of the literature (e.g., Adams \& Sykes, 2003; Bennett \& Dann, 2000; Littunen \& Tohmo, 2003; Paige \& Littrell, 2002) our study demonstrates that business owners also use other types of criteria to evaluate their success, for example societal impact and personal satisfaction. The achievement and acceptance of such criteria are neither sufficiently researched nor instructed by entrepreneurship educators (Wilson, 2004). This leaves a wide gap in the area of small business and entrepreneurship. A better understanding of the subjective success criteria that business owners use is important, because owners who fail to fulfil their personal goals are more likely to close their businesses, even when those are profitable (e.g., Bates, 2005). Understanding personal values as drivers behind business owners' choice of success criteria is equally important, because it has inherent importance on the health, well-being and financial success of business owners. Living in accordance to ones' 
values predicts long-term personal well-being and satisfaction, whereas a misfit between a person's values and choices leads to internal conflicts and distress in the long term (Bardi \& Schwartz, 2003). In turn, distress has been found to impair business owners’ financial performance (e.g., Gorgievski-Duijvesteijn, Bakker \& Giesen, 2000; Gorgievski-Duijvesteijn, Bakker, Schaufeli, Van der Veen \& Giesen, 2009).

Thus, the alignment of one's values with one’s ideas of success has multiple benefits. Insight into business owners' objective and subjective success criteria and the way they align with one's values can be used to develop more valid methods to advise business owners on how to attain and sustain satisfying careers. First, individuals embarking on an entrepreneurial path can be guided towards a specific direction based on their values. Second, existing business owners can be taught to align their values and success criteria to achieve greater well-being.

This study has been carried out among Dutch small business owners. Dutch business owners are a good sample for studying the relationship between intrinsic motivational aspects and business goals. In a worldwide comparison, the entrepreneurial activity in The Netherlands is typical for those of high-income, free market-economy countries with 2.6 percent of the population engaged in start-ups and a business-owner manager rate of 6.4 percent of the population (the respective figures in the US are 3.4 percent and 5.0 percent; Bosma, Jones, Autio \& Levie, 2008). As is typical of high-income countries, a high share of new business ownership in the Netherlands is opportunity-motivated as opposed to business ownership out of necessity, i.e. lack of alternative employment options (Bosma et al., 2008). Regarding the ease of doing business, e.g. the amount of regulatory hurdles that business owners face, the Dutch business environment is more complex than say that of the U.S. or the UK, and similar to that of other European countries such as Germany. However it should be kept in mind that evidence on the influence of regulatory environment on business ownership 
is less strong and clear than often assumed (e.g. Levie \& Autio, 2008; Van Stel, Storey \& Thurik, 2007).

The remainder of this paper is organized as follows. First, a literature review is presented on different criteria of business owners' success and a possible hierarchical ordering of success criteria. The next section introduces values theory and theorizes why specific relationships can be expected to exist between business owners' value orientations and hierarchical ordering of success criteria. After the methods section, descriptive results will be presented on specific characteristics of the sample in this study (demographics, values orientation), as compared to other populations. Next, research questions on theorized relationships will be addressed. The last section will discuss the findings and give theoretical and practical implications.

\section{Ten Criteria of Business Owners’ Success}

We reviewed the management, business, entrepreneurship and psychological literature to identify a comprehensive list of possible entrepreneurial success criteria. We started with a manual search for articles written in the past ten years in the Academy of Management (AoM) Executive, AoM Journal, AoM Practice, AoM Review, Business Ownership Research and Practice, International Journal of Entrepreneurial Behavior and Research, Journal of Business Venturing, Journal of Business and Psychology, and Journal of Small Business Management. We used a broad range of terms that could define business owners' success, ranging from business performance and entrepreneurial performance to owner-operator goals and objectives, which lead to the inclusion of 119 articles. Second, we searched Psycinfo for the terms "business owner*” or “entrepreneur*”, and "success” since January 01, 2000 and scanned 227 more articles. In addition, we conducted in-depth interviews with five business

owners. Based on our search, we have included the following, most frequently mentioned, criteria in our study (See Table 1). Note that different success criteria can relate positively to 
each other, but this is not necessarily the case. Some may even appear to be at conflict.

The first three criteria that we included have been identified as crucial to entrepreneurship: profit, growth and innovation (for example, Hitt, Ireland, Camp, \& Sexton, 2001; Lechler, 2001). These criteria are expected to relate closely to wealth generation. In line with previous literature reviews (for example, Adams \& Sykes, 2003; Julien, 1998; Paige \& Littrell, 2002), we found that growth and profitability are the two criteria most often used as performance measures in the entrepreneurship and small business literature. Innovation has been used less often as a performance criterion. Firm innovation has been argued to be a critical part of firm activity (see Adams \& Sykes, 2003; Engelen, 2002; Hitt et al., 2001; Reuf, 2002). It is often seen as a means to increase growth and profitability of a firm (e.g., Czarnitzki \& Kraft, 2009; Roberts, 1999). Its use as a success criterion, therefore, focuses on creation itself. For example, Adams and Sikes (2003) defined it as new product development, integration of technology, strategic alliances, strategic planning, and acquisitions, which they called the criterion of the inventor/developer.

The fourth criterion we identified is firm survival/ continuity, which concerns the endurance or longevity of a company. In the small business literature, articles that deal with firm survival are often about bankruptcies and survival in the short run, because of which it may not seem a very high success standard (for example Agarwal, Echambadi, Franco, \& Sarkar, 2004; Bollingtoft, Ulhoi, Madsen, \& Neergaard, 2003; Cooper, Javier GimenoGascon, \& Woo, 1994; Kropp \& Zolin, 2005; Stuart \& Abetti, 1987). Although we do acknowledge that keeping the firm out of the red may already be an accomplishment for some businesses, such as starters, this is not the way we defined this success criterion. We defined this criterion as being able to continue the business for an indefinite period of time (cf. Kuratko, Ireland, \& Hornsby, 2001). In order to have favorable long-term business prospects, the business must have good solvency, so that it would have sufficient financial means to 
finance possible large reorganizations in order to maintain its competitive advantage. Longevity of the firm as defined in this way has particular importance for family businesses, where it relates to the (financial) possibility to transfer the business to future generations (see Littunen \& Tohmo, 2003; Mariussen, Wheelock, \& Baines, 1997; Mitra, 2002; Rosenblatt, DeMik, Anderson, \& Johnson, 1990; Wang et al., 2004).

\section{Insert Table 1 about here}

A fifth criterion identified through the literature review is social and environmental performance (for example, Cornwall, 1998; Orlitzky, Schmidt, \& Rynes, 2003), or in other words contributing back to society. As with survival, we did not define this criterion as a “minimum behavioral standard”, including abiding by the law, and generally maintaining standards of honesty and integrity (cf. Campbell, 2006). In contrast, we defined it as meeting goals related to further social and environmental welfare beyond the direct economic, technical, and legal interest of the firm. This may include philanthropic behaviors, such as giving to charities, supporting community activities, and pursuing environmentally friendly practices (cf. McWilliams \& Siegel, 2001). The recent discussion of social entrepreneurship has particularly highlighted social and environmental performance as success criteria (e.g. Mair \& Marti, 2006). However, past research has identified these success criteria also in craft retail storeowners or minority business owners (Foley, 2003; Paige \& Littrell, 2002).

We have also chosen to include a variety of performance criteria of a softer nature that have been investigated in previous research. We partly build on research on business owner objectives (Kuratko, Hornsby, \& Naffziger, 1997; Newby, Watson, \& Woodliff, 2003), which showed that, in addition to financial returns or extrinsic rewards, business owners strive for several personally oriented objectives. These can be categorized as personal satisfaction/ intrinsic rewards, staff-customer relations, family related objectives, and time flexibility. 
Although far less often studied as performance criteria, owners' personal satisfaction with their business can be considered a basic measure of performance (Cooper \& Artz, 1995), which bears upon many business decisions, such as whether to invest more time and money, whether to cut back, or even to shut the business down. Several studies have identified receiving gratification from one's work as a key outcome of self-employment, indicating the importance of personal satisfaction (Bennett \& Dann, 2000; Mariussen et al., 1997; Mitra, 2002; Paige \& Littrell, 2002) and a recent review of research suggests that the satisfaction business owners derive from their jobs is more important to them than financial success (Van Praag \& Versloot, 2007). This corresponds well with the results of our in-depth interviews, in which small business owners indicated that they would only call themselves "successful" if being an entrepreneur would add to their satisfaction in general, irrespective of actual economic business performance.

Satisfied stakeholders, in particular customer satisfaction and employee satisfaction, have also been identified as important criteria in past studies. For example, they have been included in performance measures that link to business strategy, such as the Balanced Score Card, Performance Prism, and the Business Excellence model (for example Adams \& Sykes, 2003, Sapienza \& Grimm, 1997). We included satisfied stakeholders rather than "staff and customer relations”, because we perceived the latter to be a means to an end rather than endcriteria.

We have defined time and family related objectives broader as the achievement of work-life balance, which has emerged as an important criterion in the literature. Work has often been found to interfere with one's personal life (particularly among males) and one's personal life has also been found to interfere with one's work life (particularly among females; Nelson \& Burke, 2000). Mitra (2002) and Mariussen et al. (1997) identified that a subgroup of the business owners they researched chose their career to allow them more time 
with their families. They used the autonomy and flexibility that their position allowed to balance the responsibilities at work and at home. In our in depth interviews, business owners called a positive work-life balance the crowning glory of their hard work in the early start-up years.

We included public recognition as a separate criterion. This criterion emerged mainly from scanning the popular media that typically give special attention to award winning entrepreneurs and their companies and products. In addition, Kuratko et al. (1997) found that public recognition was one of business owners’ intrinsic rewards. In support of this, Corman, Perles, and Yancini (1988) found that high-technology business owners identified recognition from their peers as one of their primary motivators.

Finally, a criterion that we added based on the results from in depth interviews was "utility” or usefulness of one's product or service. This refers to the development of a product or service that not only looks good or tastes good, but serves an important function in society (c.f., Mariussen et al., 1997). For example, business owners whose products or services include microprocessors, software programs, and high-speed internet capability would likely agree that they receive much fulfillment from the knowledge that their products have enabled the management and movement of massive amounts of information.

In summary, the criteria selected were profit, growth, innovation, firm survival/continuity, contributing back to society, personal satisfaction, satisfied stakeholders (employees and customers), work-life balance, public recognition and utility or usefulness. There were other criteria that we decided not to include. For example, some criteria were too broad, such as: "success in meeting your own goals” (Escher et al., 2002). Instead, based on the acknowledgement that meeting your own goals is a legitimate success criterion, we have defined four success criteria that are related to business owners' objectives. We have not included criteria that seemed too narrow, in specific business strategy performance criteria 
that are often conceptualized as means to achieve success, rather than end goals. These include good customer relations, internal business processes, organizational learning, implementation and communication of strategies, capabilities, stakeholder contribution, leadership, people management, policy and strategy, resources, and processes.

\section{Relative Importance of Different Success Criteria}

Although many studies have defined and operationalised success criteria, only few studies determined what criteria business owners or chief executives themselves use to measure their success. Since past studies only incorporated very few of the success criteria mentioned above, it is difficult to predict their relative importance for business owners.

For example, Adams and Sikes’ (2003) sample of African-American business owners placed more emphasis on profit than on non-financial measures such as employee and customer satisfaction. In contrast, a sample of indigenous Australian business owners did not describe success in terms of financial performance at all (Foley, 2003). Their most important criterion was continuity. Newby et al. (2003) found that among business owners' objectives, personal satisfaction was the most important objective for entering and staying in business, followed by financial returns. One could argue that personal satisfaction should rank first, because striving for personal satisfaction is always the underlying objective for all other objectives, including profit maximization. However, in the same study by Newby et al. (2003), business owners rated financial returns and time flexibility higher than personal satisfaction as objectives for the future.

Finally, concerning the relative importance of profit versus social and environmental performance, there is some debate as to whether social and environmental entrepreneurship would be just a means for some businesses to increase economic performance, assuming that profit maximization is the main objective. However, other researchers assume that actors are motivated by logics of both instrumentality and appropriateness (Campbell, 2006), which 
may mean that both objectives would be equally important.

Based on this literature, financial returns, personal satisfaction and work-life balance (time flexibility) may be expected to rank high as success criteria. However, findings are equivocal. Moreover, it is yet unclear whether the various success criteria are all aspects of one underlying construct of business success, or whether business owners subjectively order these criteria on multiple dimensions. Examples of multidimensional structures that can easily come to mind are economic versus non-economic or business versus personal. Therefore, we formulated the following, exploratory research questions:

Research Question 1: How do business owners rank different criteria of entrepreneurial success?

Research Question 2: What is the underlying structure of the rank ordering of success criteria?

\section{Theory of Human Values}

Assuming that there will be variation among business owners in how they define success, we will be able to then investigate the underlying motivators of those success criteria. We postulate that business owners' success criteria reflect their value orientations. Values are stable, trans-situational goals that vary in importance and serve as guiding principles in people's lives (e.g. Schwartz \& Bardi, 2001). Values guide decision-making and motivate behaviour that is congruent with them (e.g., Bardi \& Schwartz, 2003; De Dreu \& Nauta, 2009; Schwartz, 2005, 2009). Values capture an aspect of personality that is particularly relevant to motivation (Roccas et al., 2002) and are highly stable over time (Bardi et al., in press). Given that values guide decision-making and actions, we propose that business owner's apply criteria to judge their success that are in line with their values. First empirical evidence on values and entrepreneurial goals corroborates that business owners' values may 
permeate business strategies and business success (e.g., Ajzen, 2002; Corman et al., 1988;

Koiranen, 2002; Kotey \& Meredith, 1997). Next we turn to the 10 value orientations put forth in Schwartz's value theory and then derive predictions regarding value orientations and success criteria.

\section{Insert Table 2 about here}

Schwartz’ theory has been widely validated including evidence for the near universal structure of the 10 proposed value orientations and the pattern of their relationship with one another across over 70 cultures (e.g. Schwartz \& Bardi, 2001; Schwartz et al., 2001, Schwartz, 2005) The ten value orientations are power, achievement, hedonism, stimulation, self-direction, universalism, benevolence, tradition, conformity and security (see Table 2 for definitions). The value orientations are theoretically structured based on the complimentary or conflicting nature of the motivational goal they represent. Figure 1 illustrates these relationships. Values that are close to one another are complimentary to one another. Values that are on opposite ends are conflicting with one another. A horizontal and a vertical axis divide the circle into four quadrants. One axis leads from self-enhancing to self-transcendent. The other axis leads from openness to experience to conservation. On the self-transcendent side of the circle, benevolence and universalism are adjacent to one another, because both involve a high regard for the welfare of others. Self-transcendence values are, for instance, related to whether people engage in prosocial behavior for the common good (universalism) or for the good of close others (benevolence) (Schwartz, 2009). On the opposite, selfenhancing side of the circle, the values of power and achievement are adjacent to one another, because they both involve increasing and demonstrating an individuals' own worth, i.e. selfinterested behavior. Likewise, self-direction and stimulation are both at the openness to experience side of the circle, because both involve striving for independence, new experiences 
and change, while tradition, security and conformity are on the opposite side, because these values emphasize maintaining the status quo, such as accepting and acting on tradition and adhering to group norms.

Schwartz (2005) posits that values have developed to enable us to deal with three universal tasks that all humans are confronted with 1) survival of individuals as biological organisms, 2) the need for coordinated social interaction as humans live in groups and 3) the demands of group survival and functioning. Correspondingly, he finds support for the notion that, although individuals differ concerning the importance they attach to different values, across cultures the relative importance people attribute to certain values is much more similar than different (Schwartz \& Bardi, 2001; Schwartz et al., 2001). For instance benevolence, a value that promotes cooperation within a group and thereby aids the survival of the group (and its individual members) is ranked highest across cultures, while power, which emphasizes the individual over the group, is of little importance to most people in most cultures. Furthermore, self-direction is ranked second across cultures, presumably because it has strong implications for the survival of the group. Its emphasis on independent thought and innovation ensures group survival by means of providing a motivation to find the best way of dealing with challenges.

\section{Business owners’ Success Criteria and Human Values}

Several studies have shown that business owners hold other values than non-owner managers, and that these specific value patterns transcend cultural patterns. For example, business owner/ founders placed more emphasis on the self-enhancing and openness to experience side of the values domain, such as achievement, power and self direction, and stimulation, and social power (Fagenson, 1993; Holt, 1997; Vos, 2001). In contrast, nonowner managers valued hedonistic, benevolence and universalistic values more than business owners did (Fagenson 1993; Vos, 2001). In addition, value differences discriminating 
entrepreneurial types have been associated with different preferred routes to success (Miner, 1997). For example, a desire for power has been associated with "real managers”, who would prefer large, hierarchical organizations (also Holt, 1997). On the other hand, "super sales" people believe social processes and good external relationships are important. This entrepreneurial type with a more self-transcending values profile can also lead to successful business ownership, be it via another route. Results among salespersons were in line with this contention (Swenson \& Herche, 1994), showing both self-enhancing achievement values and self transcending social values predicted high sales volume and financial performance.

Other studies have investigated specific relationships between business owners' values, business strategies and business performance. Overall, these studies show evidence for different roads to business success that can be taken by different types of business owners. For example, the self enhancing values of power and achievement were positively related to financial business success in a study by Kasser, Cohn, Kanner, and Ryan (2007). Other studies have also emphasized the importance of achievement related values as predictors of entrepreneurial success, including striving for being the number one in the market (Helmer \& Olson, 1987), and engaging in innovative behavior (development and improvement of products and methods), marketing activities, and customer service (Kotey \& Meredith, 1997).

In contrast, Gump (2007) found that values of power were negatively related to creativity, one of the preconditions for innovative behavior. Creativity positively related to values of universalism in the opposite quadrant. Kasof, Chen, Himsel, and Greenberger (2007), too, found that values of universalism, as well as self-direction, and stimulation related positively to creativity, while values of tradition, conformity, and security, negatively related to creativity. Finally, creativity, innovation and change have been related to individualism, achievement and independence, and lower values of support and conformity (Morris, Schindehutte, \& Lesser, 2002). Based on this we can expect that typical 
entrepreneurial tasks of innovation and change are more guided by an openness to change value orientation and their adjacent values of universalism and achievement.

Another line of research has focused on owners' and managers' social and environmental behavior. DeMiranda Coelho, Gouveia, and Milfont (2006) found that selftranscendence values were positively related to pro-environmental behavior. In support of this, Schultz and Zelezny (1999) found that universalism positively and power and tradition negatively related to pro-environmental attitudes (also Schwartz, 2009). Cohrs, Maes, Moschner and Kielmann (2007) found that values of universalism and benevolence are positively and values of security negatively related to human rights endorsement. Choi and Wang (2007) found that values of benevolence and integrity promote a company's corporate philanthropy. By the way, they also show that these values contribute to a company's credibility and trusting firm-stakeholder relationships, which indirectly improve a company’s financial performance. Not surprisingly, then, universalism and benevolence values have been identified as key to long term survival of family firms (Koiranen, 2002). Finally, holding the self-transcendent value of family security on top related to "Defender" business strategies (Helmer \& Olson, 1987): emphasizing quality, better prices and a limited line of products and services, which may be characteristic for successful small businesses (cf. Carland, Hoy, Boulton \& Carland, 1984).

Few studies lend support for a relationship between traditional and conformity values and successful business strategies. One study by Gatrell, Jenkins and Tucker (2001) showed that risk avoidance, smoothing and resistance to change are values shared by business-owning families. Some authors theorized such values may be shared by non-entrepreneurial small business owner/managers (England, 1975), whose criteria of success may primarily be continuance. 
In sum, the literature does lend support to our thesis that business owners personal significantly impact which criteria the owners use to define business success, but it provides insufficient information for developing hypotheses about the relationships between all ten selected success criteria and Schwartz' values. We do expect that growth and making a profit will fit the self-enhancing orientations of power and achievement, and will fall in the same quadrant in a multidimensional space. In contrast, we expect benevolence and universalism to relate positively to more social criteria; for example, work-life balance and satisfied customers and employees, and giving back to society. Furthermore, we expect that innovation would fall in the same quadrant as values related to openness to experience (self-direction and stimulation), whereas it would relate negatively with conservation values (tradition, security and conformity). These alignments are further outlined in Figure 1. Following, our third research question is:

Research Question 3: Do business owners' specific evaluations of success criteria align with their specific value orientations?

\section{Insert Figure 1 about here}

\section{Methods}

\section{Participants}

Participants were identified through network directories, business directories and drop-in visits to their place of business. Business owners were asked face-to-face or by telephone if they wanted to participate and were given the option to complete the questionnaire online or on paper. A sample of 184 business owners responded (participation rate was approximately 30 percent). The number of usable responses was 150 (38 percent female) with a mean age of 41 years ( $S D=9.2$, ranging from 23 to 60). The majority of 
business owners were educated (63 percent had received a university or university equivalent degree), had been self-employed for an average of 7.64 years ( $S D=5.39$, range of less than 1 to 43 years), were of Dutch origin (95 percent), were mainly micro-businesses employing less than 10 employees (89.1 percent), and operated mainly in service industries (for example, computer retail, beauty salons, accounting). When compared to a population-representative sample of Dutch business owners (European Social Survey, 2008), our sample was highly similar in terms of education (64 percent with at least secondary degree), national origin (95 percent Dutch), having less than 10 employees (86 percent) and mainly operating in the service industries. Business owners in our sample were younger (41 vs. 53 years) and slightly more often female (41 vs. 36 percent).

\section{Instruments}

In addition to demographic variables of the business owner (age, gender, educational level) and the business (branch, number of employees), the study included the following measures:

Criteria. The ten success criteria were presented in list form with their definition. In the questionnaire, the criteria were introduced as follows: "A number of business owners told us that a successful entrepreneur and/or his or her business has at least three of the following characteristics”. This introduction was followed by the list of definitions. To review, these were (1) profitability, (2) growth or expansion of the business, (3) innovation, (4) firm survival/continuity, (5) contributing back to society, (6) personal satisfaction, (7) satisfied stakeholders (employees and customers), (8) work-life balance, (9) public recognition and (10) utility or usefulness (see Table 1). Respondents were asked to rank order these criteria.

Values. Business owners’ personal value orientations were measured with The Portrait Values Questionnaire (PVQ; Schwartz et al., 2001). The PVQ consists of 40 statements that portray goals and aspirations that are implicitly connected to certain value orientations. For 
example, "It is very important to her to show her abilities. She wants people to admire what she does" describes someone who values achievement. Statements indicate the importance of each value to a person rather than the possession of such a trait, characteristic, or behavior. The 40 statements represent 10 main value orientations: conformity, tradition, benevolence, universalism, self-direction, stimulation, hedonism, achievement, power, and security (see Table 2 for definitions).

Respondents evaluated the statements based on how similar the person described in each statement is to himself or herself on a 6-point Likert type scale, that ranged from (6) very much like me through (3) somewhat like me to (1) not at all like me. These answers represent the value of each statement to the respondent rather than whether the respondent possesses a certain trait, characteristic, or displays a certain behavior. The internal-consistency reliabilities for our study are shown in Table 3. They ranged between .51 (tradition) and .82 (universalism). This compares to reported internal-consistency reliabilities (Schwartz et al., 2001), which range between .37 (tradition) and .79 (hedonism).

Insert Table 3 about here

\section{Analyses}

Multidimensional scaling (MDS) techniques were used to answer research questions two and three. MDS statistically analyses the similarity of objects to one another. Objects are theorized to lie on a point on a dimension, which is based on the value of that object on an attribute. The dimension represents the attribute. Multiple dimensions form a multidimensional space. The closer objects are to one another in the multidimensional space, the more similar they are to one another. The number of meaningful dimensions for a given number of objects depends on the underlying structure of the objects.

To investigate the underlying structure of the rank ordering of success criteria 
(research question 2) we performed PRINcipal Component analysis by Alternating Least Squares (Princals) on the transposed data matrix, in which the subjects, or persons, formed the variables and the objects formed the cases (Van der Kloot, 1997). This is a vector model, in which the objects are represented by dots (see Figure 2), and subjects are represented by vectors leading from the origin to its unique point in the multidimensional space (not shown in Figure 2). The estimated ranking of the objects can be projected on these vectors. To determine the number of dimensions, a solution for a large number of dimensions (six in our case) was computed and (similar to factor analysis) a scree-plot of the eigenvalues was assessed. The dimensions are then labeled using subjective criteria (also similar to factor analysis). Furthermore to test research question 3 we conducted a Proxscal analyses, which tests the alignment between the rank-ordered success criteria and business owners' value orientations. In these MDS analyses both objects (Figure 3) and subjects (not shown in Figure 3) are represented by dots.

\section{Results}

\section{Descriptive Statistics}

The value orientations of the business owners in our sample are reported in Table 4. In order to interpret value hierarchies of specific samples meaningfully, they need to be compared to pan-cultural norms (i.e., value hierarchies that have been found to be fairly stable across national cultures) and national norms (Schwartz \& Bardi, 2001; Schwartz et al., 2001) Hence we include these norms in Table 4 as well. Our sample differed to an extent from pancultural norms. Our sample seems exceptional in giving high priority to the self-oriented values self-direction and hedonism. In addition, they also valued stimulation more - seeking excitement, novelty and change. In contrast, they rated benevolence, security and conformity lower than the norm group. Comparing the results to those from national representative Dutch samples taken from the third wave of the European Social Survey (see European Social 
Survey, 2009, fieldwork conducted 2006-2007) shows that the higher ranking of selfdirection, and the lower ranking of benevolence in our sample is similar to findings among a representative sample of Dutch business owners as compared to the Dutch general representative sample, lining up with the idea that business owners may have their own set of value orientations that transcend national cultures (e.g., Busenitz \& Lau, 1996; McGrath, MacMillan, \& Scheinberg, 1992). The higher ranking of hedonism and stimulation, and the lower ranking of conformity appear to be sample specific, i.e. it was not found for either of the other Dutch samples. We would like to note that comparing the results of this study to those of the ESS needs to be done with some caution, because the ESS used a short version of the value instrument employed in the present study, the PVQ.

Insert Table 4 about here

\section{Research Question 1: Rank Ordering of Success Criteria}

In order to answer our first research question, we investigated how business owners ranked the ten success criteria. Table 5 shows the ranking of success criteria for the total sample. Personal satisfaction was the most important success criterion for the largest number of business owners (44 percent), followed by profitability and satisfied stakeholders.

Previous research has shown that business owners' goals may vary depending on individual and business demographic factors, specifically age, gender, education, and type of

business (e.g., Steward, Watson, Carland, \& Carland, 1998). For this reason, we explored if the ranking of top 5 success criteria related to demographic and business variables, and hence to what extent results can be expected to be sample dependent. Rank order correlations (Kendall's Tau B) showed no significant associations with gender (dummy coded 0-1) and education level. The age of business owners did matter: younger business owners ranked 
profitability higher than older business owners (Kendall's Tau B $=-.14, p<.05$ ). Concerning business variables, business size was an important discriminatory variable. The larger the business, the more important were continuity (Kendall's Tau $\mathrm{B}=.19, p<.01$ ) and business growth (Kendall's Tau B $=.20, p<.01$ ), and the less important was a good balance between work and private life (Kendall's Tau B $=-.15, p<.05$ ). Given that our sample was somewhat younger than a national representative sample of Dutch business owners, it can be expected that profitability would rank somewhat lower in a national representative sample.

Insert Table 5 about here

\section{Research Question 2: Underlying Structure of Success Criteria Rankings}

Concerning the underlying structure of the hierarchical ordering of success criteria (Research Question 2), results of Princals analyses showed that two dimensions could best explain the underlying structure of the hierarchical ordering of criteria for the total population; a scree-plot of the eigenvalues in a six-dimension solution (60.37, 25.81, 22.09, 15.52, 11.86, and 9.40 respectively) showed the most extreme break between the second and the third dimension. Because of this and the interpretability of the dimensions, we analyzed the results of a two-dimensional solution (see Figure 2).

Most strikingly, eight of the ten criteria clustered relatively close together, and profitability and personal satisfaction stand alone as end-markers of the two dimensions. The first dimension had an eigenvalue of 72.99 and explained 49 percent of the variance. This dimension can be labeled as person-oriented. Personal satisfaction and business growth are on the opposite ends of this dimension. The top three criteria on this dimension were: (1) “personal satisfaction” (2) "profitability” (3) "balancing work and private life”. The second dimension had an eigenvalue of 32.93, and explained 21.29 percent of variance. On this dimension, profit countered societal contribution. The top three criteria were (1) 
“profitability,” (2) “continuity,” and (3) “innovation”. Based on these criteria, this dimension can be labeled as a business-oriented dimension. Interestingly, profitability seems to be an important success criterion both in terms of business success and personal success.

Insert Figure 2 about here

\section{Research Question 3: Alignment of Success Criteria Rankings and Value Orientations}

Finally, we investigated whether business owners’ rankings of success criteria align with their value orientations. We conducted multidimensional scaling (MDS) techniques to analyze the proximity, i.e. alignment or similarity of business owners' rakings of success criteria and their personal value ratings. The results are presented in Figure 3. As shown, the traditional, business-oriented success criteria of growth, innovation and profitability together with continuity/ longevity of the business fall in the same quadrant as - i.e. are aligned with the self-enhancing value-orientations (power and achievement). This is only partly in line with our expectations, since we expected particularly innovation to relate to the openness to change value dimension, which we did not find.

Furthermore and in line with our expectations, the more socially oriented criteria having satisfied stakeholders and a good balance between work and private life fell in the same quadrant with self-transcending value orientations (universalism and benevolence).

Moreover, the success criterion personal satisfaction fell in the same quadrant with openness to change values. The success criteria utility, contributing back to society, and public recognition fall in the same quadrant as conservation values.

Figure 3 about here 


\section{Discussion and Conclusions}

This study set out to investigate business owners' own definitions of success. It furthermore aimed to explore business owners' personal value orientations as a potential predictor of variation in owners' success definitions. In sum, results regarding success definitions show that most small business owners put personal and interpersonal criteria above business criteria. The most widely used success criterion was clearly personal satisfaction. Profit ranked second, followed by satisfied stakeholders (customers and clients) and a good balance between work and private life. Multidimensional scaling indicated that a two-dimensional solution best explained the ranking of success criteria. The first dimension explained most of the variance and was labelled as person-oriented (highlighted by personal satisfaction versus business growth), the second we labelled as business-oriented (highlighted by profit versus contributing to society).

The top five ranking of success criteria differed due to business owners' age and business size. Younger business owners ranked profitability higher than older business owners. People who owned larger businesses ranked continuity/ business survival higher and balance between work and private life lower than owners of smaller businesses. These results suggest that socio-demographic personal and business characteristics may be associated with the way business owners' define success.

Beyond socio-demographic characteristics the literature suggests that the personal values owners' hold have a profound influence on the behaviour and choices they make (e.g., Hambrick, 2007; Kasser et al., 2007) - likely including the choice of criteria by which they judge their businesses' success. In line with this notion, we found that the relative importance business owners attached to success criteria related largely to their individual value orientations as expected. Business owners valuing self-enhancement (power, achievement) also put relatively more emphasis on (the traditional) success criteria of profitability and 
business growth; while business owners valuing self-transcendence (benevolence, universalism) placed relatively greater emphasis on finding a good balance between work and private life and on satisfied stakeholders. In contrast to our expectations, innovativeness was more closely aligned with self-enhancement values than with openness to change values. In addition, contributing back to society was aligned with conservation values rather than selftranscendence values.

These findings may help to explain why educators and governments amongst others find it hard to stimulate growth-oriented, innovative businesses (e.g. EIM, 2003). The value orientation underlying traditional success criteria such as growth, profitability and innovation is self-enhancement (power, achievement). In the general population, across cultures and even among business owners (cf. Table 4), self-enhancement values are of relatively little importance. Moreover, self-enhancement values are directly conflicting with selftranscendence values (benevolence, universalism) which rank among the most important values for most people and also business owners. In other words, striving for traditional business goals is conflicting with self-transcendence values (benevolence and universalism), which are important guiding principles in life for most people and also most business owners (also Schwartz \& Bilsky, 1990; Schwartz \& Bardi, 2001).

Following this line of reasoning, it should, moreover, not be surprising that of the three most widely used success criteria in business and entrepreneurship research (profit, growth, and innovation), only one criterion (profit) had been ranked by business owners in our sample to be among their top three criteria of success. Business owners ranked the criteria innovation and business growth, which relate to self-enhancement values, fifth and tenth respectively, which corresponds with the relatively low importance rating of selfenhancement values as just discussed.

In line with other values studies, such as the European Social Survey (ESS), our 
results show evidence for a typical "entrepreneurial" value profile, which might indicate a self-selection process (cf. the attraction-selection-attrition mechanisms proposed by Schneider, Goldstein and Smith, 1995). The business owners in our sample rated themselves as being more self-directed, hedonistic and seeking for excitement, novelty and change than pan-cultural norm groups. In contrast, they rated benevolence, security and conformity lower. In the ESS, Dutch business owners also ranked self-direction higher, and benevolence lower than the national average. To some extent this finding is in line with the content of these value orientations. After all, business owners create new value, and as such can be expected to emphasize openness-to-change values over conservation values. In addition, business ownership often requires investing a lot of time and effort in the work domain, which may have negative consequences for the private domain. This contrasts with benevolence values, which promotes caring for the welfare of close others. However, given the emphasis previous studies have put on 'need for achievement' as a predictor of business growth and making a profit, we might perhaps have expected business owners to place more emphasis on achievement oriented values, which was not found to be the case in our study.

\section{Limitations and Future Research}

Our study had several limitations. First, our sample size was not very large, although it is comparable to similar studies (for example, Bennett \& Dann, 2000) and in fact much larger than in most studies on the topic (Adams \& Sykes, 2003; Mitra, 2002; Olson \& Currie, 1992). Related to this, our sample consisted of Dutch business owners whose average age was slightly younger than the national average of Dutch business owners. The question remains as to what extent our findings would generalize to a broader sample, across different industries, and beyond Dutch business owners. As our results indicate, the rank ordering of success criteria might be different for samples of young business owners and owners of larger businesses. 
Replications including a larger variety of business owners and across cultures would be welcome. Such replications would need to investigate in more detail how the environment might influence business owners' values as well as success criteria. The findings of the present study may be typical for high income, democratic societies. Past sociological research has shown that the natural, economic, and social environment relate to differences in values on the national level (Díez-Nicoláz, 2003; Inglehart, 1997; Schwartz \& Sagiv, 2000). Values in low income countries were found to be security-driven rather than driven by selfexpression/openness to change. Hence, the values of business owners in low income countries might differ and consequently also the importance attributed to the various success criteria. On the other hand, results of prior studies suggest that business owners' value profiles transcendent national cultures. Future research could help to resolve this puzzle.

In addition, future research can build evidence on whether or not business owners' values and success criteria may change as they develop their business. We find that business owners' success criteria vary with age and the size of the firm. A longitudinal study would be able to disentangle 1) cohort effects, i.e. younger age groups differ in values from older age groups (Inglehart, 1997) and hence choose different success criteria, from 2) potential effects of true value change as businesses grow larger and 3) an effect of certain values driving business growth. Research to date offers equivocal findings. In line with option 2, scarce evidence suggests that values can change somewhat within individuals, for example through education and major life events (Bardi et al., in press). At the same time and consistent with option 3, research suggests that values guide behaviours (e.g. Bardi \& Schwartz, 2003).

Lastly, future research could benefit from systematically exploring further, e.g. more narrow, success criteria not included in the present study. Such a study would provide more evidence on whether or not business owners judge success criteria based on the personal and a business dimension. Moreover, based on the current study more refined hypotheses of which 
values are associated with what type of success criterion can be tested.

\section{Implications}

In spite of its limitations, the findings of our study do have implications for research and practice. First, our findings can be used to improve research aimed at predicting entrepreneurial success. A misfit between predictor and success criterion measures has been found to obscure possible relationships (for example, Rauch, Frese \& Sonnentag, 2000; Tett, Steele, \& Beauregard, 2003). Future studies can be improved if they more clearly identify the criterion of interest to both the researcher and the business owners under investigation. Our results show that the personal dimension is more important to business owners than the business dimension, and both dimensions might lead to setting conflicting goals. It is therefore advisable to use multiple criteria in order to assess business success. In addition to the traditional criteria of growth, innovation and profit, which focus only on the business dimension and mainly fit self-enhancing value orientations, researchers should take a more ecological approach, and include criteria that are relevant to multiple systems at different levels, such as the individual (personal satisfaction), the small group (family, customers and clients) and even society (contributing back to society, utility). Moreover, research should focus on possible conflicts that may occur when people attempt to strive for multiple goals.

Second, our findings have practical implications for the recruitment of nascent entrepreneurs. There has been an admirable movement by the European Commission to stimulate business ownership in the European Community (European Commission, 2003). According to the theory of vocational choice, a person will choose a career or occupation that fits with his/her self-concept (Holland, 1985). Additionally, the Attraction-Selection-Attrition theory (Schneider, et al., 1995) indicates that people become attracted to a job opportunity based on the congruence between one's own personality and personal values and an organization's goals and culture. These theories have subsequent implications for business 
ownership as a career choice, and the way we should communicate to potential business owners what it means to be an entrepreneur. In order to attract a large group of people to become business owners, it may be fruitful to provide students with a wide range of role models, with their differing profiles. This should increase the amount of interest in business ownership among those who are also capable of operating an entrepreneurial venture, but with another value profile than people who are currently drawn into entrepreneurship and would be more naturally inclined to pursue a venture outside of the norm of pursuing high growth and innovation (as is likely the case for people strongly valuing conservation).

Finally, our results have implications for policymakers, who focus much effort in motivating business owners to make a profit, grow, and innovate (EIM, 2003; European Commission, 2003). We believe that for this purpose, more insight is needed into what business owners value and strive toward. We are not devaluing the importance of profit, growth, and innovation to the continuation of a business, rather we are emphasizing that for many business owners it is only a means rather than an end itself. More importantly, it may even conflict with values business owners find really important and which are guiding principles in their lives. In order to change business owners' behavior effectively, it is necessary to speak the business owners' language and to develop solutions that help business owners achieve their true goals. For example, if an entrepreneur's objective is to increase the use of reusable glass in order to decrease the creation of waste, business plans should focus more on the distribution (a motivator) and less on the amount of profit (irrelevant).

\section{Conclusion}

This study has provided insight into the way business owners use multiple criteria to define entrepreneurial success. Results show that business owners put personal and interpersonal criteria above business criteria. Different success criteria fit different personal value orientations, which may indicate there are incompatibilities and conflicts between 
success criteria, analogous to those between value orientations. This has implications for research and practice. Most importantly, it calls for a more holistic approach to understanding business success - using multiple indicators of success. We advise that researchers and practitioners who want to stimulate business owners' performance not only focus on the performance criterion of their interest (for example growth), but also on possible conflicting criteria that business owners themselves may value (such as work-life balance, or contributing back to society). 


\section{References}

Adams, B. \& Sykes, V. (2003). Performance measures and profitability factors of successful African-American entrepreneurs: An exploratory study. Journal of American Academy of Business, 2, 418-424.

Agarwal, R., Echambadi, R., Franco, A. M., \& Sarkar, M. B. (2004). Knowledge transfer through inheritance: spin-out generation, development, and survival. Academy of Management Journal, 47, 501-522.

Ajzen, I. (2002). Residual effects of past on later behavior: Habituation and reasoned action perspectives. Personality and Social Psychology Review, 6, 107-122.

Bardi, A., Lee, J.A., Hofmann-Towfigh, N., \& Soutar , G. (in press). The structure of intraindividual value change. Journal of Personality and Social Psychology.

Bardi, A. \& Schwartz, S. H. (2003). Values and Behavior, strength and structure of relations. Personality and Social Psychology Bulletin, 10, 1207-1220.

Bates, T. (2005). Analysis of young, small firms that have closed: delineating successful from unsuccessful closures. Journal of Business Venturing 20, 343-358

Bennett, R. \& Dann, S. (2000). The changing experience of Australian female entrepreneurs. Gender, Work and Organization, 7, 75-83.

Bollingtoft, A., Ulhoi, J. P., Madsen, H., \& Neergaard, H. (2003). The effect of financial factors on the performance of new venture companies in High Tech and KnowledgeIntensive Industries: An empirical Study in Denmark. International Journal of Management, 20, 535-547.

Bosma, N., Jones, K., Autio, E \& Levie, J. (2008). Global entrepreneurship montior 2007 executive report. Babson College, London Business School and Global Entrepreneurship Research Consortium (GERA).

Busenitz, L. W. and Lau, C. M. (1996). A cross-cultural cognitive model of new venture creation: understanding entrepreneurial and immigrant decision making. Entrepreneurship Theory and Practice, 20(4): 25-37.

Campbell, J. L. (2006). Institutional Analysis and the paradox of corporate social responsibility. American Behavioral Scientist, 49, 925-938.

Carland, J. W., Hoy, F., Boulton, W. R., \& Carland, J. A. C. (1984). Differentiating entrepreneurs from small business owners: A conceptualization. Academy of Management Review, 9, 354-359.

Czarnitzki, D. and Kraft, K. (2009, forthcoming), On the Profitability of Innovative Assets, Applied Economics.

Choi, J. \& Wang, H. (2007). The promise of a managerial values approach to corporate philanthropy. Journal of Business Ethics, 75, 345-359.

Cohrs, J. C., Maes, J., Moschner, B., \& Kielmann, S. (2007). Determinants of human rights attitudes and behavior: A comparison and integration of psychological perspectives. Political Psychology, 28, 441-469.

Cooper, A. C., Javier Gimeno-Gascon, F., \& Woo, C. Y. (1994). Initial human and financial capital as predictors of new venture performance. Journal of Business Venturing, 9, 371395. 
Cooper, A. C. \& Artz, K. W. (1995). Determinants of satisfaction for entrepreneurs. Journal of Business Venturing, 10, 439-457.

Corman, J., Perles, B., \& Yancini, P. (1988). Motivational factors influencing hightechnology entrepreneurship. Journal of Small Business Management, 26, 36-42.

Cornwall, J. (1998). The entrepreneur as a building block of community. Journal of Developmental Entrepreneurship, 3, 141-148.

Czarnitzki, D. and Kornelius, K. (2009, forthcoming), On the Profitability of Innovative Assets, Applied Economics.

De Dreu, C.K.W. \& Nauta, A. (2009). Self-Interest and Other-Orientation in Organizational Behavior: Implications for Job Performance, Prosocial Behavior, and Personal Initiative. Journal of Applied Psychology, 94, 913-926.

De Miranda Coelho, J. A. P., Gouveia, V. V., \& Milfont, T. L. (2006). Valores humanos como explicadores de atitudes ambientais e intencao de comportamento pro-ambiental. [Human values as predictors of environmental attitudes and pro-environmental behavior.] Psicologia em Estudo, 11, 199-207.

Díez-Nicolás, J. (2003). Two contradictory hypotheses on globalization: Societal convergence or civilization differentiation and clash. In: R. Inglehart (ed.), Human values and social change, findings from the values surveys, Leiden, NL: Koninklijke Brill NV.

EIM. (2003). The Green Paper 'Entrepreneurship in Europe': Reaction from EIM Business \& Policy research. Zoetermeer, NL: EIM.

Engelen, E. (2002). How innovative are Dutch immigrant entrepreneurs? International Journal of Entrepreneurial Behaviour \& Research, 8, 69-92.

England, G.W. (1975). The manager and his values: an international perspective from the United States, Japan, Korea, India, and Australia. Cambridge, Massachusetts: Ballinger Publishing Co.

Escher, S., Grabarkiewicz, R., Frese, M., Steekelenburg, G. v., Lauw, M., \& Friedrich, C. (2002). The moderator effect of cognitive ability on the relationship between planning strategies and business success of small scale business owners in South Africa: A longitudinal study. Journal of Developmental Entrepreneurship, 7, 305-218.

European Commission. (2003). Green paper entrepreneurship in Europe. Brussels: Commission of the European Communities.

European Social Survey (2009). www.europeansocialsurvey.org, data from third round of European Social Survey (2006/2007) retrieved from http://ess.nsd.uib.no, last access, November, 2009.

Fagenson, E.A. (1993). Personal Value systems of men and women entrepreneurs versus managers. Journal of Business Venturing, 8, 409-430.

Foley, D. (2003). An examination of Indigenous Australian entrepreneurs. Journal of Developmental Entrepreneurship, 8, 133-151.

Gatrell, J. Jenkins, H., \& Tucker, J. (2001). Family values in family business. In G. Corbetta \& D. Montemerlo (eds.) The role of family in family business. 12th annual FBN World Conference, Rome. Egea S.p.A. FBN: Milano.

Gorgievski-Duijvesteijn, M. J., Bakker, A.B., Schaufeli, W.B. Van der Veen, H. \& Giesen, C.W.M.. (2009, forthcoming). Financial problems and psychological distress: 
Investigating reciprocal effects among business owners. Journal of Occupational and Organisational Psychology.

Gorgievski-Duijvesteijn, M. J., Giesen, C. W. M., \& Bakker, A. B. (2000). Financial problems and health complaints among farm couples: Results of a 10-year follow-up study. Journal of Occupational Health Psychology, 5, 359-373.

Gump, N. W. (2007). Creativity and self knowledge: Predicting creativity with values and vocational interests measures. Dissertation Abstracts International: Section B: The Sciences and Engineering. Vol 68(2-B), 2007, pp. 1357.

Hambrick, D.C. (2007) Upper echelons theory: An update. Academy of Management Review, 32(2), 334-343.

Helmer, T. \& Olson, S.F. (1987). The minority entrepreneur: an assessment of the correlation between personal values and company strategy, Southwest Academy of Management Sciences (March).

Hitt, M. A., Ireland, R. D., Camp, S. M., \& Sexton, D. L. (2001). Guest editors' introduction to the special issue strategic entrepreneurship: Entrepreneurial strategies for wealth creation. Strategic Management Journal, 22, 479-491.

Holland, J. L. (1985). Making Vocational Choices (2nd edition). Englewood Cliffs, New Jersey: Prentice Hall.

Holt, D.A. (1997). A comparative study of values among Chinese and U.S. entrepreneurs: Pragmatic convergence between contrasting cultures. Journal of Business Venturing, 12, 483-505.

Inglehart, R. (1997). Modernization and Post modernization, cultural, economic and political change in 43 countries. New Yersey: Princeton University Press.

Julien, P. A. (1998). The state of the art in small business and entrepreneurship. Suffolk, Great Britain: The Ipswich Book Company.

Kasof, J., Chen, C., Himsel, A., \& Greenberger, E. (2007). Creativity Research Journal, 19, 105-122.

Kasser, T., Cohn, S., Kanner, A. D., \& Ryan, R. M. (2007). Some costs of American corporate capitalism: A psychological exploration of value and goal conflicts. Psychological Inquiry, 18, 1-22.

Koiranen, M. (2002). Over 100 years of age but still entrepreneurially active in business: exploring the values and family characteristics of old Finish family firms. Family Business Review, 15, 175-187.

Kotey, B. \& Meredith, G.G. (1997). relationships among Owner/manager personal values, business strategies and business performance. Journal of Small Business Management, 35, 37-64.

Kropp, F. \& Zolin, R. (2005). Technological entrepreneurship and small business innovation research programs. Academy of Marketing Science Review, 2005, 1-14.

Kuratko, D. F., Hornsby, J. S., \& Naffziger, D. W. (1997). An Examination of owners' Goals in Sustaining Entrepreneurship. Journal of Small Business Management, 35, 24-33.

Kuratko, D. F., Ireland, R. D., \& Hornsby, J. S. (2001). Improving firm performance through entrepreneurial actions: Acordia's corporate entrepreneurship strategy. Academy of Management Executive, 15, 60-71. 
Lechler, T. (2001). Social interaction: A determinant of entrepreneurial team venture success. Small Business Economics, 16, 263-278.

Levie, J., \& Autio, E. (2008). A theoretical grounding and test of the GEM model. Small Business Economics, 31, 235-263.

Littunen, H. (2000). Entrepreneurship and the characteristics of the entrepreneurial personality. International Journal of Entrepreneurial Behaviour \& Research, 6, 295309.

Littunen, H. \& Tohmo, T. (2003). The high growth in new metal-based manufacturing and business service firms in Finland. Small Business Economics, 21, 187-198.

Mair, J. and Marti, I. (2006). Social entrepreneurship research: A source of explanation, prediction, and delight. Journal of World Business, 41, 36-44.

Mariussen, A., Wheelock, J., \& Baines, S. (1997). The family business tradition in Britain and Norway. International Studies of Management in Organizations, 27, 64-85.

McGrath, R. G., Macmillan, I. C. \& Scheinberg, S. (1992). Elitists, risk-takers, and rugged individuals? An exploratory analysis of cultural differences between entrepreneurs and non-entrepreneurs. Journal of Business Venturing. 7 (2), 115-135.

McWilliams, A., \& Siegel, D. (2001). Corporate social responsibility: a theory of firm perspective. Academy of Management Review, 26, 117-127.

Miner, J. B. (1997). The expanded horizon for achieving entrepreneurial success. Organizational Dynamics, 25, 54-67.

Mitra, R. (2002). The growth pattern of women-run enterprises: An empirical study in India. Journal of Developmental Entrepreneurship, 7, 217-237.

Morris, M., Schindehutte, M. \& Lesser, J. (2002). Ethnic entrepreneurship: do values matter? New England Journal of Entrepreneurship, 5, 35-46.

Nelson, D. L. \& Burke, R. J. (2000). Women Executives: Health, stress, and success. Academy of Management Executive, 14, 107-121.

Newby, R., Watson, J., \& Woodliff, D. (2003). Using focus groups in SME research: The case of owner-operator objectives. Journal of Developmental Entrepreneurship, 8, 237246.

Olson, S. F. \& Currie, H. M. (1992). Female entrepreneurs: Personal value systems and business strategies in a male-dominated industry. Journal of Small Business Management, 30, 49-56.

Orlitzky, M., Schmidt, F. L., \& Rynes, S. L. (2003). Corporate social and financial performance: A meta analysis. Organization Studies, 24, 403-441.

Paige, R. C. \& Littrell, M. A. (2002). Craft retailers' criteria for success and associated business strategies. Journal of Small Business Management, 40, 314-331.

Rauch, A., Frese, M., \& Sonnentag, S. (2000). Cultural differences in planning/success relationships: A comparison of small enterprises in Ireland, West Germany and East Germany. Journal of Small Business Management, 38, 28-41.

Reuf, M. (2002). Strong ties, weak ties, and islands: Structural and cultural predictors of organizational innovation. Industrial and Corporate Change, 11, 427-449. 
Roberts, P.W. 1999. Product innovation, product-market competition and persistent profitability in the U.S. pharmaceutical industry. Strategic Management Journal, 20, 655-670

Roccas, S., Sagiv, L., Schwartz, S. H. \& Knafo, A. (2002). The big five personality factors and personal values. Personality and Social Psychology Bulletin, 28, 789-801.

Rosenblatt, P. C., DeMik, L., Anderson, R. M., \& Johnson, P. A. (1990). The family in business. San Fransisco, Oxford: Jossey-Bass Publishers.

Sapienza, H. and Grimm, C. (1997) Founder characteristics, start-up process and strategy / structure variables as predictors of short-line railroad performance. Entrepreneurship Theory and Practice, 22, 5-24.

Schneider, B., Goldstein, H. W., \& Smith, D. (1995). The ASA Framework: an update. Personnel Psychology, 48, 747-773.

Schultz, P. W., \& Zelezny, L. (1999). Values as predictors of environmental attitudes: Evidence for consistency across 14 countries. Journal of Environmental Psychology, 19, 255-265.

Schwartz, S.H. (2005). Basic human values: Their content and structure across cultures. In A. Tamayo \& J. Porto (Hrsg.) Valores e trabalho [Values and work], pp. 21-55. Brasilia: Editoa Vozes.

Schwartz, S.H. (2009). Basic Values: How they motivate and Inhibit prosocial behavior, in M. Mikulincer and P. Shaver, (eds.), Herzliya Symposium on Personality and Social Psychology, Vol.1. Washington: American Psychological Association Press.

Schwartz, S.H. \& Bilsky, W. (1990). Toward a theory of universal content and structure of values: extensions and cross-cultural replications. Journal of Personality and Social Psychology, 58 (5), 878-891.

Schwartz, S.H. \& Bardi, A. (2001). Value Hierarchies Across Cultures: taking a similarities perspective. Journal of Cross-Cultural Psychology, 32: 268-290.

Schwartz, S. H., Melech, G., Lehmann, A., Burgess, S., Harris, M., \& Owens, V. (2001). Extending the cross-cultural validity of the theory of basic human values with a different method of measurement. Journal-of-Cross-Cultural Psychology, 32, 519-542.

Schwartz, S.H. \& Sagiv, L. (2000). Value consensus and importance: A cross-national study. Journal of Cross-Cultural Psychology, 31, 465-497

Stewart, W.H., Jr., Watson, W.E., Carland, J.A.C., \& Carland, J.W. (1998). A proclivity for entrepreneurship: A comparison of entrepreneurs, small business owners, and corporate managers. Journal of Business Venturing, 14, 189-214.

Stuart, R. \& Abetti, P. A. (1987). Start-up ventures: towards the prediction of initial success. Journal of Business Venturing, 2, 215-230.

Swenson, M.J. \& Herche, J. (1994). Social values and salesperson performance: an empirical examination. Journal of the Academy of Marketing Science, 22, 283-289.

Tett, R. P., Steele, J. R., \& Beauregard, R. S. (2003). Broad and narrow measures on both sides of the personality-job performance relationship. Journal of Organizational Behavior, 24, 335-356.

Van der Kloot, W. A. (1997). Meerdimensionale schaaltechnieken voor gelijkenis en keuzedata. Ruimtelijke modellen voor psychologie, marktonderzoek en andere 
wetenschappen. [Multidimensional scaling techniques for similarity and preference data. Spatial Models for psychology, marketing research and other sciences.] Utrecht, The Netherlands: Lemma.

Van Praag, C.M., \& Versloot, P.H. 2007. What is the value of entrepreneurship? A review of recent research, Small Business Economics, 29: 351-382.

Van Stel, A., Storey, D., \& Thurik, R. (2007). The effect of business regulations on nascent and young business entrepreneurship. Small Business Economics, 28, 171 - 186.

Vos, R. (2001). Generating entrepreneurial and administrative hierarchies of universal human values as a basis for identifying entrepreneurial and administrative potential across contexts. Tuscaloosa, Alabama: Unpublished doctoral thesis.

Wang, Y., Watkins, D., Harris, N., \& Spicer, K. (2004). The relationship between succession issues and business performance: Evidence from UK family SMEs. International Journal of Entrepreneurial Behaviour \& Research, 10, 59-84.

Wilson, K. (2004) Entrepreneurship Education at European Universities and Business Schools. Survey report. EFER and EFMD. 


\section{Table 1}

\section{Entrepreneurial Success Criteria}

1. Profitability: high yields, good profit margin.

2. Growth: growth in the number of employees, sales, market share and / or distribution.

3. Innovation: introduction of new products or production methods.

4. Firm Survival/Continuity: enables generational transfer or can be sold with a profit.

5. Contributing back to society: socially conscious, sustainable production methods.

6. Personal Satisfaction: through attaining important things in life, such as autonomy, challenge, security, power, creativity, etc.

7. Satisfied Stakeholders: satisfied and engaged employees, satisfied customers.

8. Good Balance between Work and Private Life: positive mutual influence between work and private life, allows time for yourself, family, and friends.

9. Public Recognition: good reputation, prizewinner.

10. Utility or usefulness: organization fulfills a need in society; it provides an important service or product.

Note. In the questionnaire definitions were given in alphabetical order. 
Table 2

\section{Schwartz Value Dimensions}

Power: Social status and prestige, control or dominance over people and resources. (I like to be in charge and tell others what to do. I want people to do what I say.)

Achievement: Personal success through demonstrating competence according to social standards. (Being very successful is important to me. I like to stand out and to impress other people.)

Hedonism: Pleasure and sensuous gratification for oneself. (I want to enjoy life. Having a good time is very important to me.)

Stimulation: Excitement, novelty, and challenge in life. (I look for adventures and like to take risks. I want to have an exciting life.)

Self-direction: Independent thought and action-choosing, creating, exploring. (I think it’s important to be interested in things. I am curious and try to understand everything.)

Universalism: Understanding, appreciation, tolerance and protection for the welfare of all people and for nature. (I think it is important that every person in the world should be treated equally. I want justice for everybody, even for people I don’t know.)

Benevolence: Preservation and enhancement of the welfare of people with whom one is in frequent personal contact. (I always want to help the people who are close to me. It's very important to me to care for the people I know and like.)

Tradition: Respect, commitment and acceptance of the customs and ideas that traditional culture or religion provide the self. (I think it is important to do things the way I learned from my family. I want to follow their customs and traditions.)

Conformity: Restraint of actions, inclinations, and impulses likely to upset or harm others and violate social expectations or norms. (I believe that people should do what they're told. I think people should follow rules at all times, even when no one is watching.)

Security: Safety, harmony and stability of society, of relationships, and of self. (The safety of my country is very important to me. I want my country to be safe from its enemies.) 
Table 3.

Descriptive statistics and Reliability Coefficients of Demographic and Business

\section{Variables and Value Orientations}

\begin{tabular}{|c|c|c|c|c|}
\hline & $N$ & $M$ & $S D$ & $\begin{array}{c}\text { Crohnbach's } \\
\text { alpha }\end{array}$ \\
\hline 1. Age* & 137 & 41.29 & & \\
\hline 2. Level of education & 144 & 4.24 & 1.08 & \\
\hline 3. Number of employees & 125 & 5.48 & 20.77 & \\
\hline 4. Conformity & 144 & 3.08 & 1.00 & .71 \\
\hline 5. Tradition & 144 & 2.70 & .81 & .51 \\
\hline 6. Benevolence & 144 & 4.35 & .84 & .70 \\
\hline 7. Universalism & 144 & 4.16 & .92 & .82 \\
\hline 8. Self-direction & 144 & 4.60 & .94 & .55 \\
\hline 9. Stimulation & 144 & 4.31 & 1.11 & .81 \\
\hline 10. Hedonism & 144 & 4.43 & 1.00 & .73 \\
\hline 11. Achievement & 144 & 3.98 & .98 & .75 \\
\hline 12. Power & 144 & 3.38 & .96 & .66 \\
\hline 13. Security & 144 & 3.74 & .86 & .61 \\
\hline
\end{tabular}

* 0 = male, 1 = female $(41.29 \%$ of respondents is female $)$ 
Table 4.

Value Orientations among our sample of Dutch business owners' as compared to Pan-Cultural PVQ Norms and results for Dutch representative

\begin{tabular}{|c|c|c|c|c|c|c|}
\hline & \multicolumn{2}{|c|}{$\begin{array}{l}\text { Values of the Dutch Business } \\
\text { Owners (present sample) }\end{array}$} & \multirow{2}{*}{$\begin{array}{c}\begin{array}{c}\text { Values of a representative } \\
\text { sample of Dutch business owners } \\
\text { (ESS) }\end{array} \\
\text { Mean rank }\end{array}$} & \multicolumn{2}{|c|}{$\begin{array}{c}\text { Pan Cultural PVQ-norms } \\
\text { (Schwartz, 2005) }\end{array}$} & \multirow{2}{*}{$\begin{array}{c}\text { Values of a representative } \\
\text { Dutch sample (ESS) } \\
\text { Mean rank }\end{array}$} \\
\hline & $\begin{array}{c}\text { Mean rating } \\
(s d)\end{array}$ & Mean rank & & Mean rank & $\begin{array}{c}\text { Mean rating } \\
(s d)\end{array}$ & \\
\hline Self-direction & $4.60(0.94)$ & 1 & 1 & 2 & $4.23(0.87)$ & 3 \\
\hline Hedonism & $4.43(1.00)$ & 2 & 4 & 4 & $4.02(1.13)$ & 4 \\
\hline Benevolence & $4.35(0.84)$ & 3 & 2 & 1 & $4.63(0.86)$ & 1 \\
\hline Stimulation & $4.31(1.11)$ & 4 & 7 & 7 & $3.47(1.22)$ & 8 \\
\hline Universalism & $4.16(0.92)$ & 5 & 3 & 5 & $3.96(0.82)$ & 2 \\
\hline Achievement & $3.98(0.98)$ & 6 & 9 & 6 & 3.94 (1.03) & 9 \\
\hline Security & $3.74(0.86)$ & 7 & 5 & 3 & 4.16 (1.05) & 5 \\
\hline Power & $3.38(0.96)$ & 8 & 10 & 9 & $3.00(1.12)$ & 10 \\
\hline Conformity & $3.08(1.00)$ & 9 & 6 & 8 & $3.21(0.89)$ & 6 \\
\hline Tradition & $2.70(0.81)$ & 10 & 8 & 10 & $2.60(0.81)$ & 7 \\
\hline
\end{tabular}


samples from the European Social Survey (ESS) using a short version of the PVQ

\section{Table 5}

\section{Ranking of Success Criteria by 150 Dutch Business Owners}

\begin{tabular}{|c|c|c|c|c|c|}
\hline Success Criteria & $N$ & $M$ & $S D$ & Rank & $\begin{array}{l}\text { Percent } \\
\text { First } \\
\text { Choice }\end{array}$ \\
\hline Personal Satisfaction & 150 & 7.87 & 3.04 & 1 & 44 \\
\hline Profitability & 150 & 6.44 & 3.19 & 2 & 15.3 \\
\hline Satisfied Stakeholders (Clients \& Employees) & 150 & 6.23 & 2.95 & 3 & 7.3 \\
\hline Balance between Work and Private Life & 150 & 5.81 & 3.19 & 4 & 12.7 \\
\hline Innovation & 150 & 5.03 & 3.15 & 5 & 5.3 \\
\hline Firm survival/ Continuity & 150 & 4.40 & 3.20 & 6 & 5.3 \\
\hline Utility/ Usefulness & 150 & 4.32 & 2.70 & 7 & 6 \\
\hline Contributing back to Society & 150 & 3.80 & 2.89 & 8 & 1.3 \\
\hline Public Recognition & 150 & 3.46 & 2.70 & 9 & 1.3 \\
\hline Growth & 150 & 2.76 & 2.57 & 10 & 1.3 \\
\hline
\end{tabular}


Figure 1.

Expected Relationships Between Value Orientations and Ranking of Success Criteria

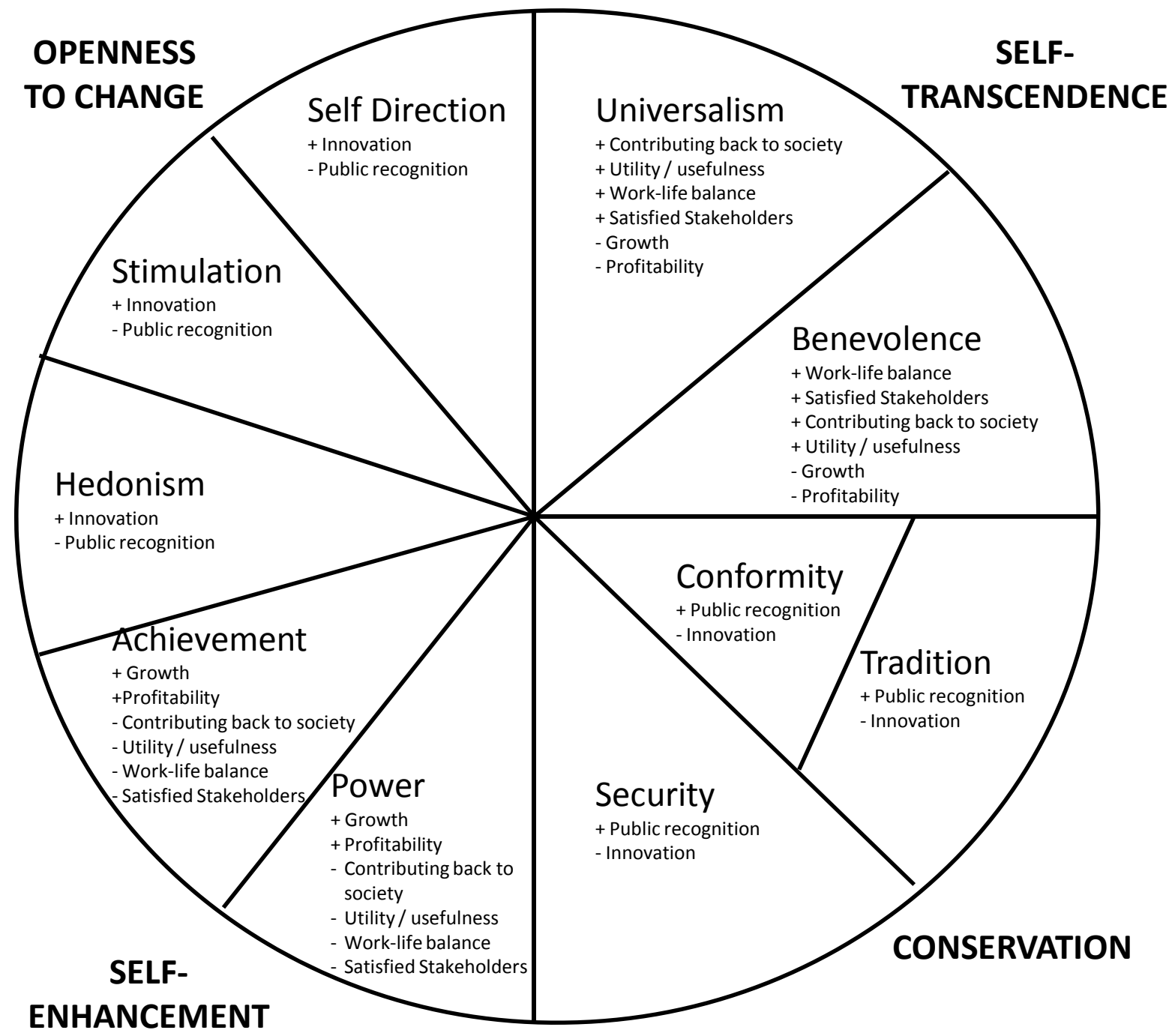


Figure 2.

Underlying Structure of Success Criteria Rankings (MDS Princals Solution; $N=144$

Business Owners)

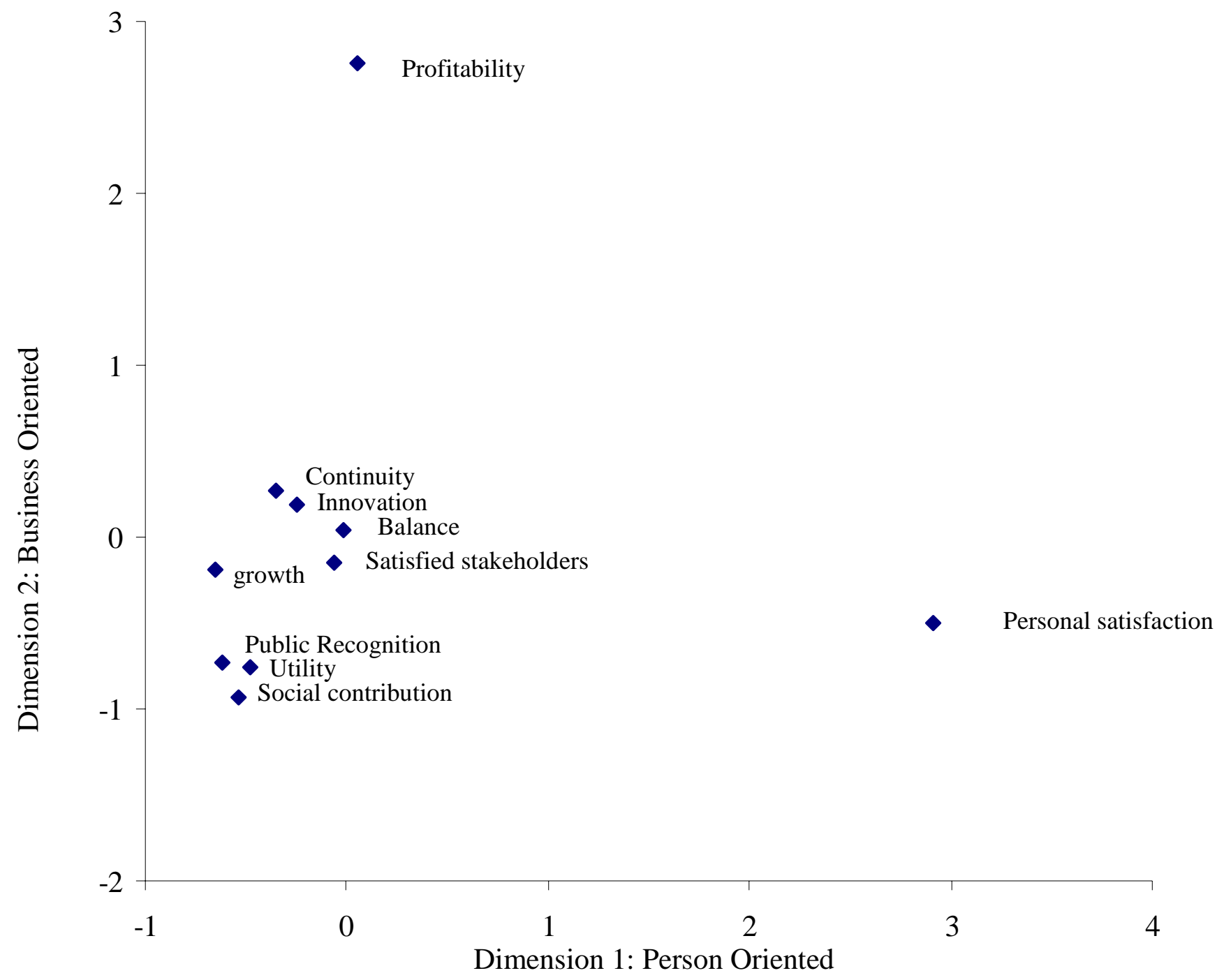


Figure 3.

Alignment of Value Orientation and Success Criteria Rankings (MDS Proxscal Solution, N= 144 Business Owners)

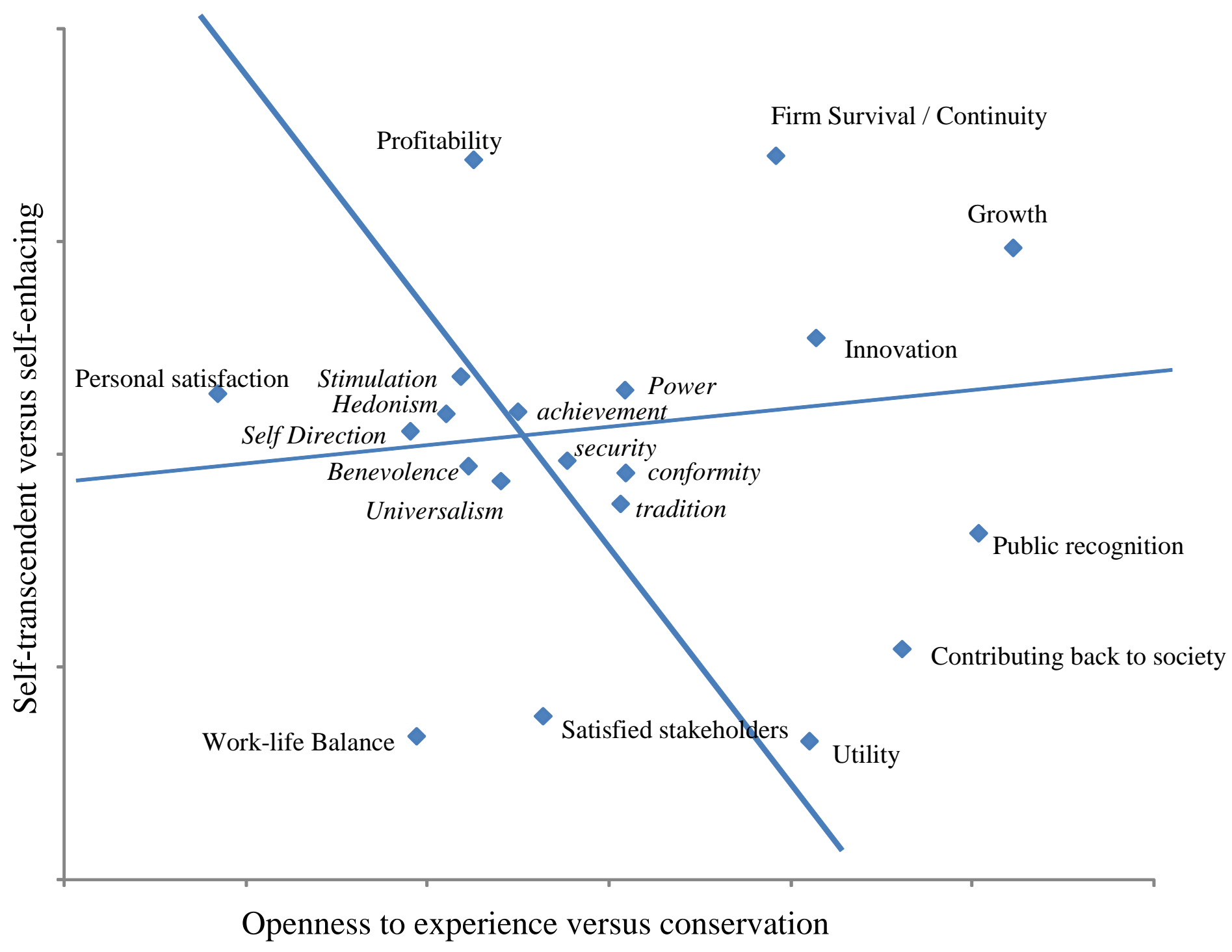

